\title{
Age Adjusted Charlson Comorbidity Index: Predictor of 90-Day Mortality after Radical Cystectomy
}

\author{
Haroon N, Nadeem $\mathrm{M}$ and Ather $\mathrm{MH}^{*}$
}

Aga Khan University, Stadium Road, Karachi, Pakistan

*Corresponding author: Ather MH, Aga Khan University, P O Box 3500, Stadium Road, Karachi 74800, Pakistan, Fax: +92 213 34934294, Tel: +92 213 34864778, E-mail: hammad.ather@aku.edu

Citation: Haroon N, Nadeem M, Ather MH (2016) Age Adjusted Charlson Comorbidity Index: Predictor of 90-Day Mortality after Radical Cystectomy. J Surg Oper Care 1(2): 204. doi: 10.15744/2455-7617.1.204

Received Date: March 24, 2016 Accepted Date: April 27, 2016 Published Date: April 29, 2016

\begin{abstract}
Objective: To evaluate the impact of age adjusted Charlson's comorbidity index (ACCI) in predicting 90-day mortality in patients undergoing radical cystectomy for Muscle Invasive Bladder Cancer (MIBC) in a low volume center.

Methods: Retrospective cohort study performed at a university hospital during a period of 1989 to 2012. Charts were reviewed for various clinical, demographic factors in ascertaining the ACCI. The data was computed and analyzed to determine the 90-day mortality. Logistic regression was applied to determine association between Charlson's co-morbidity index and 90 day mortality.

Results: 201 had radical cystectomy (RC) for muscle invasive bladder cancer (MIBC) during the period, however, 175 patients were found eligible and reviewed, 16 excluded for incomplete record or loss to followup. Baseline variables were comparable among the three categories of ACCI. Fourteen patients died during 90-day period (8\%) and eight out of them had ACCI $\geq 4$. On univariate regression analysis, high ACCI score, histology and adjuvant chemotherapy was found to be statistically significant variables; however, on multivariate regression only high ACCI score and histology were strong predictors of 90-day postoperative mortality. ACCI $>4$ and histology squamous cell cancer (SCC) increases the odds of 90 days post-operative mortality by 13 fold.

Conclusions: Age adjusted CCI $>4$ and tumor histology are significantly associated with 90 days postoperative mortality in patients undergoing radical cystectomy for muscle invasive urothelial cancer. Therefore, these variables should be taken into account while deciding about patient management preoperatively. Appropriate patient counseling and preparation should be done to reduce post-operative mortality.

Keywords: Age adjusted Charlson comorbidity index; Radical cystectomy; 90-day mortality
\end{abstract}

\section{Introduction}

Urothelial cancer (UC) of bladder is the second most common genitourinary malignancy [1]. It is estimated that 15210 people will die of urinary bladder cancer within United States alone in the year 2013 [2]. Surveillance Epidemiology and End Results (SEER) data showed that majority of bladder cancer patients are 65 years or older at the time of diagnosis with co morbidities which further increases the risk of complications [2-4].

Radical cystectomy is considered the gold standard in the management of muscle invasive bladder cancer (MIBC) and high-risk non-muscle invasive bladder cancer. Despite improvement in postoperative care this therapy is still associated with significant perioperative mortality ranging from 2.6-7.3\% [5,6]. Several contemporary series have investigated the impact of comorbidities on patient's mortality and prognosis after radical cystectomy $[7,8]$. Using data from these work models can be developed to identify patients with higher likelihood of complications and peri operative care can be modified to improve the outcome and overall survival [3].

Comorbidity indices and preoperative modeling can substantiate decision-making and improve clinical counseling accuracy. Charlson comorbidity index (CCI) was developed in 1987 to see the impact of comorbid conditions in predicting 1-year mortality of medical inpatients [9]. It was further adjusted for age by adding one extra point for each decade of life after 50 years of age [10]. The role of adjusted Charlson's comorbidity index (ACCI) as predictive tool for 90 days mortality in patients undergoing radical cystectomy has been demonstrated in few studies; however, we feel that the tool has to be validated by multiple centres and with varying workload $[11,12]$. Additionally, since the current is a generic tool and should be adjusted for other pertinent variables related to muscle invasive urothelial cancer i.e. histology, grade and stage, that can potentially impact 90 days mortality. These variables have not been evaluated in previous studies for their impact on the outcome. In order to analyze the impact of these other variables we have designed this study to determine the role of age ACCI in predicting 90 days mortality after adjusting for these variables in patients who underwent RC for MIBC at a lower volume center. 


\section{Material and Methods}

This is a retrospective cohort study of patients who underwent RC and standard lymphadenectomy over a period of 23 years i.e. from February 1989 to March 2012. Patients whose files were missing and who had received neo-adjuvant chemotherapy were excluded. Required files were retrieved using International Classification of Diseases, $9^{\text {th }}$ revision (ICD-9) procedure codes (57.71, 68.8) and were reviewed during July and August 2012.

Records were reviewed by urology resident on a structured proforma that included patient's socio-demographic (Age and gender) and clinical characteristics American Society of Anesthesiologists (ASA) score, pathological stage, grade, nodal status, adjuvant chemotherapy, lymph node counts, histology, and urinary diversion). Comorbidities were also recorded from face sheets \&/or initial assessment forms of confidential files and ACCI was calculated from online calculator available on website http://www. medal.org/OnlineCalculators/ch1/ch1.13/ch1.13.01.php. 90-day mortality was assessed as study's primary end point and included patients who expired within 90 days of surgery. ACCI was assessed at various level, certain parameters like demographics co morbidities assessed pre operatively, second set of information on tumor pathology at 4 week after surgery and than lastly at three months.

\section{Statistical Analysis}

Data was checked for wild codes and errors. Continuous variables were analyzed as mean + standard deviation for data with normal distribution and median with inter-quartile ranges for skewed data. Categorical variables were taken as proportions and percentages. Comparison of outcomes i.e. 90 days mortality between groups was performed with Chi square test or Fischer exact test. $p$-value less than 0.05 were considered statistically significant. Patients were categorized into three ACCI groups i.e. 0 - $1,2-3$ and $\geq 4$.

Univariate logistic regression was used to evaluate the impact of main exposure i.e. ACCI and covariates i.e. gender, pT-stage, pNstage, grade of tumor, adjuvant therapy on 90 day mortality. Initial multivariable regression model included statistically significant variables at $20 \%$ level of significance and clinically significant (statistically insignificant variables). Final model included main exposure and significant covariates. Association of CCI with mortality was presented as adjusted odds ratio with $95 \%$ confidence interval. All statistical analysis was done with SPSS version $19^{\mathrm{mm}}$ (IBM Corp, NY, USA).

\section{Results}

A total of 201 patients underwent RC with urinary diversion during the study period. Eight patients were lost to follow up and another 18 patients' records were missing. Our final study population consisted of 175 patients. There was no statistically significant difference ( $\mathrm{p}$ value $>0.1$ ) between all the three ACCI categories in terms of socio-demographic and clinical characteristics shown in table 1. Mean age in three ACCI categories was $61 \pm 11.8,61+14.0$ and $62+11.9$ years, respectively. Most of the patients were male (79\%) with an ASA 2 (61\%) and CCI 0-1 (67\%) category. Majority (68\%) of the patients had muscle invasive node negative disease of them $39 \%$ had extravesical disease. $78 \%$ had urothelial cell cancer and 19\% received adjuvant chemotherapy.

\begin{tabular}{|c|c|c|c|}
\hline \multicolumn{4}{|c|}{ CHARLSON COMORBIDITY SCORE } \\
\hline Characteristics & $\begin{array}{c}\text { SCORE } 0-1 \\
n=117\end{array}$ & $\begin{array}{c}\text { SCORE } 2-3 \\
n=34\end{array}$ & $\begin{array}{c}\text { SCORE } 4 \text { or more } \\
n=24\end{array}$ \\
\hline Mean age + SD (Years) & $61 \pm 11.8$ & $61+14.0$ & $62+11.9$ \\
\hline \multicolumn{4}{|c|}{ GENDER } \\
\hline Male & $94(80.3 \%)$ & $26(76.5 \%)$ & $19(79.8 \%)$ \\
\hline Female & $23(19.7 \%)$ & $8(23.5 \%)$ & $5(20.2 \%)$ \\
\hline \multicolumn{4}{|c|}{ ASA } \\
\hline $1(n=36)$ & $20(17.1 \%)$ & $8(23.5 \%)$ & $8(33.3 \%)$ \\
\hline $2(n=107)$ & $76(65 \%)$ & $20(58.8 \%)$ & $11(45.8 \%)$ \\
\hline $3(n=30)$ & $21(17.9 \%)$ & $4(11.8 \%)$ & $5(20.8 \%)$ \\
\hline $4(n=2)$ & 0 & $2(5.9 \%)$ & 0 \\
\hline \multicolumn{4}{|c|}{ NODAL STATUS } \\
\hline Negative & $76(65 \%)$ & $26(76.5 \%)$ & $13(54.2 \%)$ \\
\hline positive & $41(35 \%)$ & $8(23.5 \%)$ & $11(45.8 \%)$ \\
\hline \multicolumn{4}{|c|}{ p T Stage } \\
\hline T1 & $27(23.1 \%)$ & $2(5.9 \%)$ & $3(12.5 \%)$ \\
\hline T2 & $36(30.8 \%)$ & $10(29.4 \%)$ & $7(29.2 \%)$ \\
\hline T3 & 25 (21.4\%) & $10(29.4 \%)$ & $3(12.5 \%)$ \\
\hline T4 & 18 (15.4\%) & $7(20.6 \%)$ & $6(25 \%)$ \\
\hline T0 & $11(9.4 \%)$ & $5(14.7 \%)$ & $5(20.9 \%)$ \\
\hline
\end{tabular}




\begin{tabular}{|c|c|c|c|}
\hline \multicolumn{4}{|c|}{ Grading } \\
\hline G1 & $12(6.8 \%)$ & $6(3.4 \%)$ & $4(2.28 \%)$ \\
\hline G2 & $79(45.1 \%)$ & $13(7.4 \%)$ & $14(8 \%)$ \\
\hline G3 & $26(14.8 \%)$ & $15(8.5 \%)$ & $6(3.4 \%)$ \\
\hline \multicolumn{4}{|c|}{ Histology } \\
\hline UC & $94(80.3 \%)$ & $26(76.5 \%)$ & $16(66.7 \%)$ \\
\hline SCC & $8(6.8 \%)$ & $1(2.9 \%)$ & $2(8.3 \%)$ \\
\hline Others & $15(12.8 \%)$ & $7(20.6 \%)$ & $6(25 \%)$ \\
\hline \multicolumn{4}{|c|}{ DIVERSION } \\
\hline Ileal conduit & $99(84.6 \%)$ & $31(91.2 \%)$ & $23(95.8 \%)$ \\
\hline Neobladder & $18(15.4 \%)$ & $3(8.8 \%)$ & $1(4.2 \%)$ \\
\hline \multicolumn{4}{|c|}{ Adjuvant chemotherapy } \\
\hline Yes & $21(17.9 \%)$ & $4(11.8 \%)$ & $9(37.5 \%)$ \\
\hline No & $96(82.1 \%)$ & $30(88.2 \%)$ & $15(62.5 \%)$ \\
\hline
\end{tabular}

ASA: American society of anesthesia; UC: urothelial cancer; SCC: squamous cell cancer Table 1: Describing baseline variables among three ACCI groups

Fourteen patients died during 90-day period (8\%) and eight out of them had CCI $\geq 4$. Table 2 shows that on univariate regression analysis, high ACCI score, histology and adjuvant chemotherapy came out to be statistically significant; however, on multivariate regression only high CCI score and histology came out to be strong predictors of 90-day mortality. Age adjusted CCI $>4$ and histology (squamous cell carcinoma, SCC) increases the odds of 90 days post-operative mortality by 13 fold (Table 3 ).

\begin{tabular}{|c|c|c|}
\hline VARIABLE & CRUDE OR (95 \% CI) & P-value \\
\hline \multicolumn{3}{|c|}{ CCI SCORE } \\
\hline $0-1$ & 1 & \\
\hline $2-3$ & $0.67(0.07-6.2)$ & \\
\hline$\geq 4$ & $11.2(3.2-38.4)$ & 0.00 \\
\hline GENDER & $1.058(0.27-4.0)$ & 0.9 \\
\hline \multicolumn{3}{|c|}{ GRADE OF TUMOR } \\
\hline G1 & 1 & \\
\hline G2 & $0.7(0.13-3.6)$ & \\
\hline G3 & $1.19(0.21-6.6)$ & 0.6 \\
\hline N STAGE & $1.0(0.34-3.3)$ & 0.9 \\
\hline \multicolumn{3}{|c|}{ T STAGE } \\
\hline T1 & 1 & \\
\hline $\mathrm{T} 2$ & $0.7(0.06-8.2)$ & \\
\hline T3 & $1.5(0.15-15.9)$ & \\
\hline T4 & $1.92(0.18-20)$ & \\
\hline T0 & $18.0(0.58-553.5)$ & 0.78 \\
\hline \multicolumn{3}{|c|}{ HISTOLOGY } \\
\hline UC & 1 & \\
\hline SCC & $10.5(2.4-44.6)$ & \\
\hline Others & $2.21(0.53-9.1)$ & 0.006 \\
\hline $\begin{array}{c}\text { ADJUVANT } \\
\text { CHEMOTHERAPY }\end{array}$ & $0.39(0.12-1.26)$ & 0.11 \\
\hline
\end{tabular}

CCI: Charlson co morbidity index; UC: urothelial cancer; SCC: squamous cell cancer Table 2: Showing univariate analysis of factors affecting 90 day mortality

\begin{tabular}{|c|c|c|}
\hline VARIABLE & Adjusted OR (95\% CI) & P-value \\
\hline \multicolumn{3}{|c|}{ CCS } \\
\hline $\mathbf{0 - 1}$ & 1 & \\
\hline $\mathbf{2 - 3}$ & $0.85(0.08-8.2)$ & 0.001 \\
\hline 4 OR MORE & $13.6(3.3-56.1)$ & \\
\hline
\end{tabular}




\begin{tabular}{|c|c|c|}
\hline VARIABLE & Adjusted OR (95\% CI) & P-value \\
\hline \multicolumn{3}{|c|}{ HISTOLOGY } \\
\hline UC & 1 & \\
\hline SCC & $13.7(2.44-77.3)$ & 0.01 \\
\hline OTHERS & $1.61(0.45-11.9)$ & \\
\hline \multicolumn{3}{|c|}{ ADJUVANT CHEMOTHERAPY } \\
\hline NO & $0.88(0.22-3.48)$ & 0.8 \\
\hline YES
\end{tabular}

UC: urothelial cancer; SCC: squamous cell cancer

Table 3: Showing multivariable logistic regression analysis of factors affecting 90-day mortality

\section{Discussion}

Radical cystectomy and bilateral lymphadenectomy is considered standard in the management of muscle invasive and highgrade urothelial cancer. Local recurrence rate is as low as $4 \%$ for node negative disease and $15-20 \%$ for node positive disease [6]. Complications following radical cystectomy are related to the age and comorbid conditions, the extirpative surgical procedure, urinary diversion and bowel related. There are various factors affecting complications following radical cystectomy. The hospital volume, case mix, surgeons skills are major factors influencing post surgical complications. Reporting surgical complications following radical cystectomy a standardized and reproducible method should be used. The modified Clavian system is one such system commonly used in the reporting post radical cystectomy morbidity. The prediction of surgical complications is vital to indicate RC in appropriate patient. The CCI is one such system studied in predicting morbidity.

This retrospective cohort study was conducted to determine the role of ACCI in predicting 90 days mortality in patients who underwent radical cystectomy for muscle invasive urothelial cancer, and we found that ACCI score and histology as the strong predictors of 90-day mortality. The 90-day mortality in our cohort is on the higher end of the spectrum; this is partly because significant number of patients had a high ACCI and partly because ours is a low volume centre. Aziz, et al. [13] in a prospective European Multicenter Cohort noted that the 30-, 60-, and 90-d mortality rates in the development cohort (n; 597) were 2.7\%, $6.7 \%$, and $9.0 \%$, respectively. ACCI $>4$ and SCC increases the odds of 90 days post-operative mortality by 13 fold.

Preoperative predictive scoring including age and comorbidities proves to be helpful for counseling of patients preoperatively. It also helps to stratify patients according to the level of care required postoperatively to avoid morbidity and mortality. Several studies have discussed the value of predictive models to preempt morbidity and mortality in patients after radical cystectomy. Based on certain preoperative and postoperative variables, these models are devised to risk stratify patients before surgery [14-16].

CCI is a validated index to categorize comorbidities having impact on various medical conditions. It constitutes 19 medical conditions weighted 1 to 6 (Range 0-37) according to their ability to influence mortality [17]. During its validation phase, age was found to be an independent factor for short-term mortality from a comorbid disease. To account for advancing age, one point is added for each decade of life over the age of 50 years [9]. ACCI had comparable predictive capacity to Isbarn nomogram developed to predict 90-day mortality based on SEER data [18].

Contemporary literature places age and comorbidities as major considerations when it comes to treatment of muscle invasive bladder cancers [19-23]. Studies have shown conflicting data on CCI as Miller, et al. showed CCI to be independently associated with cancer specific mortality whereas, Koppie, et al. found that ACCI was associated with overall survival in patients who underwent radical cystectomy for urothelial cancer $[18,21,24]$. Moreover, certain studies proved that patients with low ACCI had better overall survival as compared to those who had high ACCI $[25,26]$. Our study, however, proved that CCI was independent predictor of 90-day postoperative mortality.

Pathologic T stage is considered one of the effective prognostic factors for advanced bladder cancer Mayr, et al. found ASA correlate better with predicted mortality than CCI (without age adjustment) however in the current study T stage and ASA were not associated with 90 day mortality probably because of low statistical power due to small sample size $[12,27,28]$.

Our study shows 90 -day mortality of $8 \%$ that is in the upper range of reported 90 -day mortality (2.3-7\%). This fact may be explained by the fact that our institute is low volume center as far as surgery for MIBC is concerned. Moreover, $23 \%$ of our patients had histopathology other than UC along with 33\% of patients from high ACCI category; both of these variables are shown to increase the odds of 90 -day mortality as per our results.

The limitations of current work included retrospective nature of the study with data stretched over 23 years. Although the method of reviewing comorbidity was uniform, however, it is not devoid of non-differential misclassification. Data concerning certain variables i.e. BMI, albumin, estimated blood loss in surgery and intention for surgery (palliative/curative intent) was missing. Selection bias at the time of patient selection could play a role, since patients with comorbidities are managed non-operatively. However, despite that bias CCI stands out as independent predictor after adjusting for other factors i.e. histology and adjuvant therapy. 
Lund, et al. in his population-based study raised the importance of tumor biology playing a role in preoperative mortality. Histologic grading is a recognized prognostic factor for urothelial cancer and in our study, multivariate analysis also demonstrated histology as an independent factor for 90 day mortality [24].

\section{Conclusion}

Age adjusted CCI $>4$ and tumor histology are significantly associated with 90 days mortality in patients undergoing radical cystectomy for muscle invasive urothelial cancer. Therefore, these variables should be taken into account while deciding about patient management preoperatively. Appropriate patient counseling and preparation should be done to reduce post-operative mortality.

\section{Acknowledgment}

Dr. Ghulam Murtaza for help in statistical analysis

\section{References}

1. Jemal A, Murray T, Ward E, Samuels A, Tiwari RC, et al. (2005) Cancer statistics, 2005. CA Cancer J Clin 55: 10-30.

2. Siegel R, Naishadham D, Jemal A (2013) Cancer statistics, 2013. CA Cancer J Clin 63: 11-30.

3. Novotny V, Hakenberg OW, Froehner M, Zastrow S, Leike S, et al. (2013) Systematic Assessment of Complications and Outcome of Radical Cystectomy Undertaken with Curative Intent in Patients with Comorbidity and over 75 Years of Age. Urol Int 30: 195-201.

4. Froehner M, Brausi MA, Herr HW, Muto G, Studer UE (2009) Complications following radical cystectomy for bladder cancer in the elderly. Eur Urol 56: 443-54.

5. Gregg JR, Cookson MS, Phillips S, Salem S, Chang SS, et al. (2011) Effect of preoperative nutritional deficiency on mortality after radical cystectomy for bladder cancer. J Urol 185: 90-6.

6. Boström PJ, Kössi J, Laato M, Nurmi M (2009) Risk factors for mortality and morbidity related to radical cystectomy. BJU int 103: 191-6.

7. Fairey A, Chetner M, Metcalfe J, Moore R, Todd G, et al. (2008) Associations among age, comorbidity and clinical outcomes after radical cystectomy: results from the Alberta Urology Institute radical cystectomy database. J Urol 180: 128-34.

8. Megwalu II, Vlahiotis A, Radwan M, Piccirillo JF, Kibel AS (2008) Prognostic impact of comorbidity in patients with bladder cancer. Eur Urol 53: 581-9.

9. Charlson ME, Pompei P, Ales KL, MacKenzie CR (1987) A new method of classifying prognostic comorbidity in longitudinal studies: development and validation. J chronic dis 40: 373-83.

10. Extermann M (2000) Measuring comorbidity in older cancer patients. Eur J cancer 36: 453-71.

11. Mayr R, May M, Martini T, Lodde M, Comploj E, et al. (2012) Comorbidity and performance indices as predictors of cancer-independent mortality but not of cancer-specific mortality after radical cystectomy for urothelial carcinoma of the bladder. Eur Urol 62: 662-70.

12. Mayr R, May M, Martini T, Lodde M, Pycha A, et al. (2012) Predictive capacity of four comorbidity indices estimating perioperative mortality after radical cystectomy for urothelial carcinoma of the bladder. BJU Int 110: E222-7.

13. Aziz A, May M, Burger M, Palisaar RJ, Trinh QD, et al. (2014) Prediction of 90-day mortality after radical cystectomy for bladder cancer in a prospective European multicenter cohort. Eur Urol 66: 156-63.

14. Morgan TM, Keegan KA, Barocas DA, Ruhotina N, Phillips SE, et al. (2011) Predicting the probability of 90-day survival of elderly patients with bladder cancer treated with radical cystectomy. J Urol 186: 829-34.

15. Isbarn H, Jeldres C, Zini L, Perrotte P, Baillargeon-Gagne S, et al. (2009) A population based assessment of perioperative mortality after cystectomy for bladder cancer. J Urol 182: 70-7.

16. Abdollah F, Sun M, Schmitges J, Thuret R, Djahangirian O, et al. (2012) Development and validation of a reference table for prediction of postoperative mortality rate in patients treated with radical cystectomy: a population-based study. Ann Surg Oncol 19: 309-17.

17. O'Connell RL, Lim LL (2000) Utility of the Charlson comorbidity index computed from routinely collected hospital discharge diagnosis codes. Methods Inf Med 39: 7-11.

18. Taylor JM, Feifer A, Savage CJ, Maschino AC, Bernstein M, et al. (2012) Evaluating the utility of a preoperative nomogram for predicting 90-day mortality following radical cystectomy for bladder cancer. BJU Int 109: 855-9.

19. Hollenbeck BK, Miller DC, Taub DA, Dunn RL, Khuri SF, et al. (2006) The effects of adjusting for case mix on mortality and length of stay following radical cystectomy. J Urol 176: 1363-8.

20. Stroumbakis N, Herr HW, Cookson MS, Fair WR (1997) Radical cystectomy in the octogenarian. J Urol 158: 2113-7.

21. Prout GR, Wesley MN, Yancik R, Ries LA, Havlik RJ, et al. (2005) Age and comorbidity impact surgical therapy in older bladder carcinoma patients. Cancer 104: 1638-47.

22. Miller DC, Taub DA, Dunn RL, Montie JE, Wei JT (2003) The impact of co-morbid disease on cancer control and survival following radical cystectomy. J Urol 169: 105-9.

23. Nielsen ME, Shariat SF, Karakiewicz PI, Lotan Y, Rogers CG, et al. (2007) Advanced age is associated with poorer bladder cancer-specific survival in patients treated with radical cystectomy. Eur urol 51: 699-706.

24. Koppie TM, Serio AM, Vickers AJ, Vora K, Dalbagni G, et al. (2008) Ageâ€ adjusted Charlson comorbidity score is associated with treatment decisions and clinical outcomes for patients undergoing radical cystectomy for bladder cancer. Cancer 112: 2384-92.

25. Lund L, Jacobsen J, Clark P, Borre M, Nørgaard M, et al. (2010) Impact of comorbidity on survival of invasive bladder cancer patients, 1996-2007: a Danish population-based cohort study. Urology 75: 393-8.

26. Yoo S, You D, Jeong IG, Hong JH, Ahn H, et al. (2011) Does radical cystectomy improve overall survival in octogenarians with muscle-invasive bladder cancer? Korean J urol 52: 446-51. 
27. Stein JP, Lieskovsky G, Cote R, Groshen S, Feng AC, et al. (2001) Radical cystectomy in the treatment of invasive bladder cancer: long-term results in 1,054 patients. J Clin Oncol 19: 666-75.

28. Thrasher JB, Frazier HA, Robertson JE, Dodge RK, Paulson DF (1994) Clinical variables which serve as predictors of cancerâ€ specific survival among patients treated with radical cystectomy for transitional cell carcinoma of the bladder and prostate. Cancer 73: 1708-15.

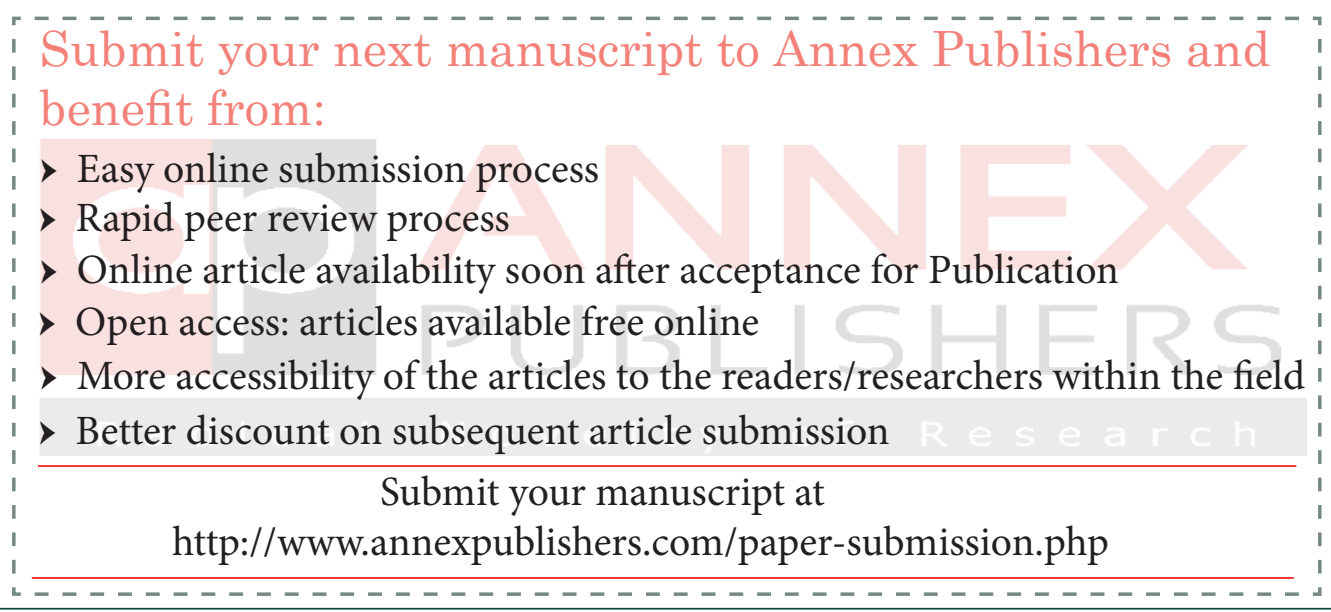

